\title{
Preparation of EVA/PVA/PU Multi-component Water-based Adhesive
}

\author{
Huo Ning-bo ${ }^{1, a^{*}}$, Zhao Chun-hai ${ }^{2, b}$ \\ ${ }^{1}$ Dept.of txtile and chemical engineering, Binzhou Polytechnic College, Binzhou 256603,China \\ ,2Dept.of bioengineering , Binzhou Polytechnic College, Binzhou 256603,China \\ ahuoningbo@outlook.com, 'zhaochunhai@126.com
}

Keywords: EVA, PVA, PU, Blending, Water-based Adhesive

\begin{abstract}
The stability, compatibility, bond strength and other parameters of the polymer emulsion system were investigated. The effects of different additives and additives content on the water resistance of water-based adhesive were studied. The results showed that the system stability is good when the content of PU in EVA/PU blend system is below $20 \%$, the system can maintain a good compatibility when the EVA/PU ratio between 85/15 and 70/30, DA-103, BF-24 and U54 are suitable as the main raw materials of the blending system, ethylene glycol with its content lower than $2 \%$ is suitable as the assistant of the system. With the investigation of shear strength, water resistance, opening time and other factors, the optimum formula is: EVA emulsion 55\%, PVA emulsion 30\%, PU emulsion $14.5 \%$, ethylene glycol $0.5 \%$ (mass fraction, relative to the total adhesive).
\end{abstract}

\section{Introduction}

Water-based adhesion has the characteristics of safety, environmental protection and easy to use, its application is increasingly wide [1]. The physical blending is an important means of polymer modification. Blending with two or more than two kinds of polymer emulsion is the most direct and simple method to preparae new water-based adhesives [2,3]. Although EVA emulsion is applied widely in the field of water-based adhesives, but its water resistance of film is not very ideal because of lack of strong polar groups and too much plastic, and the strength of bond strength is not high [4]. PVA is a kind of polymer materials can be natural degradation and environmental friendly, it can effectively improve film-forming of the emulsion system and stick relay. Complete hydrolysis type PVA is particularly important in improving water resistance [5]. PU molecules with carbamate group have strong polarity and highly active, with good affinity to a lot of base material. However, PU emulsion has higher cost compared with EVA emulsion [6]. Therefore, Applying the blending technology for preparation of EVA/PVA/PU multi-component water-based adhesion, the system stability, compatibility, adhesive strength, water resistance and opening time were studied.

\section{Test Section}

Test Materials. EVA emulsion(DA-101, DA-103, DA-104), industrial grade, Taiwan Dalian Chemical Co., Ltd.. PVA emulsion (BF-24, BF-28, BC-24), industrial grade, Taiwan Changchun Chemical Co., Ltd.. PU emulsion (DISPERCOLL U54, DISPERCOLL U42, DISPERCOLL U53), industrial grade, Bayer (China) Co., Ltd.. ethylene glycol (PEG 8000), industrial grade, American Dow Chemical Company.

Testing Instruments. Tensile testing machine,Instron3367, Enstel Ron Co., Ltd.. Electric mixer, DJ1C-100, XinPei equipment (Shanghai) Co., Ltd.. Intelligent electronic stripping tester, XLW-100N, Jinan LanGuang mechanical and electrical technology Co., Ltd..

Preparation of Adhesive. Taking a certain quality of PVA solid powder, stirring and dissolved in hot water, 20\% PVA emulsion is prepared with being static and cooling. EVA and PU emulsion are mixed in the flask with fixed proportion, the mixture is been stirring with 300rpm for 20min, a certain amount of $20 \%$ PVA emulsion is added and mixed for $20 \mathrm{~min}$, adding additives and stirring for $30 \mathrm{~min}$ to homogeneity, discharging. 
Viscosity Determination [6]. Determination was performed according to 11175-2002 GB/T standard.

Shear Strength Test. Preparing plane $8 \mathrm{~cm}$ x $5 \mathrm{~cm}$ specimens from beech wood, being coated on the surface of the tested adhesive, gelatinizing $0.25 \mathrm{~g}$ with glue coating area $5 \mathrm{~cm} \mathrm{x} 5 \mathrm{~cm}$, bonding after being placed $7 \mathrm{~d}$ at room temperature, according to the standard of GB/T17200-1997, shear strength will be tested with tensile testing machine determination.

Peel Strength Test. According to GB/T2792- 1998 standard.

Open Time Test [7]. The adhesive is coated on the surface of experiment wood, the shortest time lap will be recorded after producing adhesion between two pieces of wood.

Water Resistance Test. The adhesive is coated in the experiment with beech wood surface, uniform coating $0.25 \mathrm{~g}$ with coating area $5 \mathrm{~cm} \times 5 \mathrm{~cm}$, being placed for $24 \mathrm{~h}$. Wood cracking rate were observed after $8 \mathrm{~h}$ soaked in $100^{\circ} \mathrm{C}$ water.

\section{Results and Discussion}

Stability of Blending System. PVC has good water solubility and good stability in the complex emulsion. Therefore, the stability of EVA emulsion and PU emulsion determines the storage stability of the blending system, and then affects the adhesion of the emulsion to the interface. The static stability of blending emulsion system was investigated, and the results were shown in Table 1.

Table 1 Stability of the complex emulsion

\begin{tabular}{|l|l|l|l|l|l|}
\hline No. & $\begin{array}{l}\text { EVA } \\
(\mathrm{w} / \mathrm{w}, \%)\end{array}$ & $\begin{array}{l}\text { PU } \\
(\mathrm{w} / \mathrm{w}, \%)\end{array}$ & Solid content(\%) & 90d static stability & $\begin{array}{l}\text { 90d static stability with } \\
\mathrm{pH} 7-7.5\end{array}$ \\
\hline 1 & 100 & 0 & 55 & No change & No change \\
\hline 2 & 90 & 10 & 52 & No change & No change \\
\hline 3 & 80 & 20 & 51 & Viscosity increase & No change \\
\hline 4 & 75 & 25 & 48.5 & Viscosity increase & No change \\
\hline 5 & 70 & 30 & 47 & Appear gel & No change \\
\hline 6 & 0 & 100 & 24 & No change & No change \\
\hline
\end{tabular}

The stability of blending emulsion is worse than that of EVA and PU emulsion. To prevent the hydrolysis of vinyl acetate, $\mathrm{pH}$ of EVA emulsion will be controlled in about 5.5, while the PU emulsion $\mathrm{pH}$ in about 7. When the PU and EVA emulsion blend, EVA latex particles will absorb a large amount of PU latex, colloidal particles bonding with hydrogen, and ultimately becoming formation of flocculation. Static stability of the blend system will be more influenced by PU emulsion content.

Precipitation phenomena were not found in a certain $\mathrm{pH}$ range, because, under certain $\mathrm{pH}$, the latex particle surface emulsifier or ionic groups have a certain amount of charge, electric double layer structure formed in the surrounding. There is an electrostatic repulsion between the latex particles. It is difficult to approach each other, thus the stability of emulsion is being kept.

Considering the poor water resistance of PU and stability of the system, the content of PU in EVA/PU blend system will be less than $20 \%$.

Compatibility of Blending System. EVA and PU latex film are only one glass transition temperature (Tg), and the two component blend system will have two Tg. According to Tg determined by the differential scanning calorimetry (DSC) method, the compatibility of different ratio of the blend system will be studied. 
Table 2 Tg value of DSC

\begin{tabular}{|l|l|l|l|}
\hline EVA/PU ratio & EVA Tg $\left({ }^{\circ} \mathrm{C}\right)$ & $\operatorname{PU~Tg}\left({ }^{\circ} \mathrm{C}\right)$ & Tg difference $\left({ }^{\circ} \mathrm{C}\right)$ \\
\hline $100 / 0$ & 7 & - & - \\
\hline $85 / 15$ & 9.5 & 54.4 & 44.9 \\
\hline $80 / 20$ & 11.7 & 54.4 & 42.8 \\
\hline $70 / 30$ & 11.5 & 55.6 & 43.8 \\
\hline $60 / 40$ & 10.3 & 56.5 & 46.2 \\
\hline $0 / 100$ & - & 58.8 & - \\
\hline
\end{tabular}

The results showed that the two Tg of the blending system gradually separated from the blending ratio. Visible from the table 2, when the EVA/PU ratio between 85/15 and 70/30, the two Tg values are closer, which can be considered that the compatibility of the two components of the blend is better.

Determination of Adhesion Properties of Different Emulsion. Wood and packaging industry for water-based glue dosage accounted for more than half the water of glue dosage. Wood, PP sheet, a paper were selected as binder to measure wood / timber shear strength and peeling strength of PP/PP and PP / paper. Different EVA, PVA and PU emulsion tests were selected, as shown in table 3.

Table 3 Adhesion property of different emulsion

\begin{tabular}{|c|c|c|c|}
\hline NO. & Parameter & $\begin{array}{l}\text { Shear strength } \\
\text { (Mpa) }\end{array}$ & $\begin{array}{l}\text { Peeling strength } \\
(\mathrm{KN} / \mathrm{m})\end{array}$ \\
\hline DA103 & $\begin{array}{l}60 \% \text { solid content, viscosity } 2000 \pm 500 \text { cPs,pH } 5.5 \\
\pm 1.0 \text {, } \operatorname{Tg} 0 \pm 2{ }^{\circ} \mathrm{C}\end{array}$ & 9.31 & $0.73 / 0.16$ \\
\hline DA104 & $\begin{array}{l}55 \% \text { solid content, viscosity } 2000 \sim 3000 \text { cPs,pH5.5 } \\
\pm 1.0, \mathrm{Tg}-15 \pm 5^{\circ} \mathrm{C}\end{array}$ & 6.95 & 0.30/0.09 \\
\hline DA101 & $\begin{array}{l}55 \% \text { solid content, viscosity } 1500 \sim 250 \text { cPs } 0, \mathrm{pH} 5.5 \\
\pm 1.0, \mathrm{Tg} 0 \pm 2^{\circ} \mathrm{C}\end{array}$ & 8.67 & $0.48 / 0.12$ \\
\hline BF-24 & $\begin{array}{l}20 \% \text { solid content, viscosity 60cps, degree of hydrolysis } \\
98.8 \%, \mathrm{pH} 5-7\end{array}$ & 5.50 & $0.26 / 0.07$ \\
\hline BF-28 & $\begin{array}{l}20 \% \text { solid content, viscosity } 65 \mathrm{cps} \text {, degree of hydrolysis } \\
87.5 \% \text {,pH5-7 }\end{array}$ & 4.08 & $0.23 / 0.06$ \\
\hline BC-24 & $\begin{array}{l}20 \% \text { solid content, viscosity } 49 \mathrm{cps} \text {, degree of hydrolysis } \\
79 \% \text {,pH5-7 }\end{array}$ & 2.95 & $0.20 / 0.03$ \\
\hline U54 & $\begin{array}{l}50 \% \text { solid content, viscosity } 40-400 \text { cps,pH6-9, } \\
\text { Minimum activation temperature } 45-55^{\circ} \mathrm{C}\end{array}$ & 15.18 & $0.90 / 0.29$ \\
\hline U53 & $\begin{array}{l}40 \% \text { solid content, viscosity } 50-600 \text { cps,pH6-9, } \\
\text { Minimum activation temperature } 45-55^{\circ} \mathrm{C}\end{array}$ & 10.91 & $0.53 / 0.24$ \\
\hline U42 & $\begin{array}{l}50 \% \text { solid content, viscosity } 150-800 \text { cps,pH6-9, } \\
\text { Minimum activation temperature } 100^{\circ} \mathrm{C}\end{array}$ & 8.57 & $0.62 / 0.18$ \\
\hline
\end{tabular}

Shown in table 3, DA104 adhesion is poor, this is because the stripping transformation temperature is low, the film used is soft, cohesive strength is small, thus cohesive failure occurred in a tensile test. There is no cure after a long time of DA101 coating, open time is too long, which may be due to its low viscosity. he hydrolysis degree of BF-28 and BC-24 is low, the bond strength is low, and the water resistance is slightly worse. Due to the low solid content, U53 bonding performance is poor. As the temperature is higher, the bond performance of U42 is poor at the same temperature. Therefore, this study selected DA103, BF-24, U54 three kinds of water-based emulsion as adhesive composition.

Effect of Additives on the Open Time of the Adhesive System. The open time of emulsion system is closely related to the evaporation process of the solvent system. In order to adjust the water-based adhesive open time, various additives often be added, especially alcohols have a great influence on the open time. Table 4 shows effect of adding the quality fraction of $1 \%$ of the different 
additives to the EVA/PVA/PU emulsion system, respectively, to the open time of the film (film volume $100-120 \mathrm{~g} / \mathrm{m}^{2}$ ).

Table 4 Effect of additives on the open time of the adhesive system

\begin{tabular}{|l|l|l|l|l|l|}
\hline Additives & Ethanol & $\begin{array}{l}\text { 1,3-propylene } \\
\text { glycol }\end{array}$ & Glycol & n-heptane & Acetone \\
\hline $\begin{array}{l}\text { Open time } \\
\text { (s) }\end{array}$ & 12 & 40 & 35 & $\begin{array}{l}\text { Destruction of emulsion } \\
\text { system, Gel forming }\end{array}$ & $\begin{array}{l}\text { Destruction of emulsion } \\
\text { system, Gel forming }\end{array}$ \\
\hline
\end{tabular}

As can be seen from table 4, the open time of the coating is changed obviously when the additive is added to the system. By adding the same amount, the more the number of hydroxyl groups on the open time, the system is more obvious. This is mainly because the hydroxyl basic body has a strong hydrophilic, to a certain extent, the system delay the evaporation rate of water. If the opening time is too long, the drying rate is slow. So the choice is ethylene glycol as the additive system, while n-heptane and acetone is not suitable as the additive system.

Effect of Ethylene Glycol on the Adhesive System Stability. Ethylene glycol joins in the extended opening hours, at the same time, which also makes the cohesive force of the adhesive system decreased, stability decreases, while influences the adhesive bonding. Different amounts of ethylene glycol added in emulsion system with a certain proportion EVA/PVA/PU, we can examine the adhesive system stability, the open time after filming and the shear strength of adhesive system for wood. Results are shown in Table 5.

Table 5 Influence of the amount of ethylene glycol on the adhesive system

\begin{tabular}{|l|l|l|l|l|l|}
\hline Ethylene glycol amount(w/w,\%) & 0 & 1 & 2 & 5 & 8 \\
\hline Open time (s) & 8 & 35 & 50 & 73 & 98 \\
\hline Shear strength(Mpa) & 7.71 & 7.07 & 5.82 & 4.48 & 3.85 \\
\hline System stability(30d) & No change & No change & No change & Gel & Gel \\
\hline
\end{tabular}

As can be seen from table 5 , when the addition of ethylene glycol is greater than $5 \%$, the shear strength of the EVA/PU (75/25) system is decreased by $41.9 \%$, and the emulsion system is not stable. From the point of view of open time control, the content of ethylene glycol below $2 \%$ is appropriate.

Composition Optimization of Blending System. According to the above the results of single factor experiments, content of EVA emulsion (A), polyvinyl alcohol (PVA) (B) and ethylene glycol (C) as the three factors, 3 levels with each factor, hree factors three levels orthogonal experiment table was designed, as shown in Table 6.

Table 6 Orthogonal design of composition optimization

\begin{tabular}{|l|l|l|l|}
\hline No. & A (\%) & B (\%) & C (\%) \\
\hline 1 & 50 & 25 & 0.5 \\
\hline 2 & 55 & 30 & 1 \\
\hline 3 & 60 & 35 & 1.5 \\
\hline
\end{tabular}

With a total of 100 of the mass fraction of EVA emulsion, PVA emulsion, PU emulsion and ethylene glycol, by testing the bond strength emulsion for wood, shear strength, cracking rate and the open time as the indexes, experimental results are shown in Table 7.

Table 7 Result of orthogonal experiment of composition optimization

\begin{tabular}{|l|l|l|}
\hline No. & Factors & Results \\
\hline
\end{tabular}




\begin{tabular}{|c|c|c|c|c|c|c|c|}
\hline & A & B & C & Shear strength(Mpa) & Cracking rate(\%) & Open time(s) \\
\hline \multicolumn{2}{|l|}{1} & 50 & 25 & 1 & 8.7 & 35 & 35 \\
\hline \multicolumn{2}{|l|}{2} & 50 & 30 & 1.5 & 9.2 & 20 & 42 \\
\hline \multicolumn{2}{|l|}{3} & 50 & 35 & 0.5 & 10.5 & 10 & 18 \\
\hline \multicolumn{2}{|l|}{4} & 55 & 25 & 1.5 & 10.2 & 15 & 42 \\
\hline \multicolumn{2}{|l|}{5} & 55 & 30 & 0.5 & 11.0 & 10 & 20 \\
\hline \multicolumn{2}{|l|}{6} & 55 & 35 & 1 & 8.7 & 5 & 35 \\
\hline \multicolumn{2}{|l|}{7} & 60 & 25 & 0.5 & 11.5 & 10 & 12 \\
\hline \multicolumn{2}{|l|}{8} & 60 & 30 & 1 & 9.6 & 5 & 35 \\
\hline \multicolumn{2}{|l|}{9} & 60 & 35 & 1.5 & 8.0 & 0 & 42 \\
\hline \multirow{4}{*}{$\begin{array}{l}\text { Shear } \\
\text { strength }\end{array}$} & M1 & 9.5 & 10.1 & 9.0 & & & \\
\hline & M2 & 10.0 & 9.9 & 9.1 & & & \\
\hline & M3 & 9.7 & 9.1 & 11 & & & \\
\hline & $\mathrm{R}$ & 0.5 & 1.0 & 2.0 & & & \\
\hline
\end{tabular}

From table 7, ethylene glycol addition has the greatest effect on the shear strength, at the same time, impact the opening time of the adhesive, and PVC content influences on the cracking rate greatly. Shear strength of formula 1, 6, 8 and 9 is low, this is caused by the poor system compatibility. Because of the influence of ethylene glycol, shear strength of 2, 4, 9 formula is slightly lower. From the analysis of the water resistance, when the PU content is high, the water resistance is poor. When shear strength is greater than $10 \mathrm{MPa}$ and water resistance test cracking rate is less than $10 \%$, it is generally believed that the adhesive has good bonding strength and water resistance. Therefore, the 5 and 7 formula 3 are the better prescriptions. From the open time, prescription 7 has a short time, followed by prescription 3, and prescription 5 has a long opening time maintaining good water resistance and adhesive strength. Therefore, as the comprehensive analysis, the optimum prescription of water based adhesive is A2B2C1. The proportion of each component is EVA emulsion 55, PVA emulsion 30, PU emulsion 14.5, ethylene glycol 0.5 .

\section{Conclusion}

Within the appropriate $\mathrm{pH}$ range, when the ratio of EVA/PU is between 85/15 and 70/30, the EVA and PU emulsion blend has good compatibility.According to the test results of wood / wood shear strength and peeling strength of PP/PP and PP / paper, DA103, BF-24, U54 three emulsions are selected as components composition of the water-based adhesive.The additives were screened as a more appropriate open time and the system stability was isbetter when the content of ethylene glycol is less than 2\%.Content of EVA emulsion (A), polyvinyl alcohol (PVA) (B) and ethylene glycol (C) as the three factors, through orthogonal test, better prescription is obtained: EVA emulsion 55, PVA emulsion 30, PU emulsion 14.5, ethylene glycol 0.5 (mass fraction, relative to the total amount of adhesive).

\section{References}

[1] L. SHI, X.G. GE, Z.Z. YANG, The present situation development trend and application prospect of adhesives in China, J. China Adhesives, 8(2005) 44-51.

[2] H. Kaname, K. Takashi, I. Motoki, Study on Preparation and Formation Mechanism of n-Alkanol/Water Emulsion Using $\alpha$-Cyclodextrin, J. Chem Pharm Bull, 11(2007)1620-1625.

[3] J.Pn.Kokni, K. Tokkyo, Japan Patent 51.98239. (1976) 
[4] H.W. LIU, W.M. YUAN, The current situation and development of VAE emulsion at home and abroad, J. China Adhesives, 2(2005) 46-48.

[5] X.M. CUI, Market status and development prospect of polyvinyl alcohol at home and abroad, J. Shanghai Chemical industry, 4(2011) 34-39.

[6] W.J. GUO, H.Q. FU, Y.F. LI, Study on the Mechanical and Adhesive Properties of Waterborne Polyurethane with Multiple Modifications, J. Journal of Chemical Engineering of Chinese Universities, 2(2009)246-251.

[7] Z.H. WEN, Y.N. CHEN, S.H. WU, Waterborne polyurethane adhesives, J. China Adhesives, 4(2004)55-58.

Note: Fund Project, Binzhou science and technology development project, project number 2013ZC0705 